\title{
Functional Independence of Layer IV Barrels in Rodent Somatosensory Cortex
}

\author{
DANIEL GOLDREICH, HAROLD T. KYRIAZI, AND DANIEL J. SIMONS \\ Department of Neurobiology, University of Pittsburgh School of Medicine, Pittsburgh, Pennsylvania 15261
}

\begin{abstract}
Goldreich, Daniel, Harold T. Kyriazi, and Daniel J. Simons. Functional independence of layer IV barrels in rodent somatosensory cortex. J. Neurophysiol. 82: 1311-1316, 1999. Layer IV of rodent primary somatosensory cortex is characterized by an array of whiskerrelated groups of neurons, known as "barrels." Neurons within each barrel respond best to a particular whisker on the contralateral face, and, on deflection of adjacent whiskers, display relatively weak excitation followed by strong inhibition. A prominent hypothesis for the processing of vibrissal information within layer IV is that the multiwhisker receptive fields of barrel neurons reflect interconnections among neighboring barrels. An alternative view is that the receptive field properties of barrel neurons are derived from operations performed on multiwhisker, thalamic inputs by local circuitry within each barrel, independently of neighboring barrels. Here we report that adjacent whisker-evoked excitation and inhibition within a barrel are unaffected by ablation of the corresponding adjacent barrel. In supragranular neurons, on the other hand, excitatory responses to the ablated barrel's associated whisker are substantially reduced. We conclude that the layer IV barrels function as an array of independent parallel processors, each of which individually transforms thalamic afferent input for subsequent processing by horizontally interconnected circuits in other layers.
\end{abstract}

\section{N T R O D U C T I O N}

Sensory areas of the cerebral cortex are characterized by collections of interconnected neurons having similar receptive fields. The extent to which these local circuits interact remains poorly defined, even at the earliest stages of cortical processing. For example, some models of simple-cell orientation selectivity in cat visual cortex assume antagonistic interactions between separate minicolumns serving the same retinal location but activated by stimuli having orthogonal orientations (Crook et al. 1997; Sillito et al. 1980). Other models base orientation selectivity on convergent thalamic input solely (Ferster 1987; Hubel and Wiesel 1962; Reid and Alonso 1995) or in conjunction with locally mediated, iso-orientation excitation and/or inhibition (Ferster 1988; Troyer et al. 1998). Layer IV of rodent somatosensory cortex contains anatomically identifiable collections of neurons, called barrels, that represent distinctly different peripheral locations, i.e., facial whiskers (Woolsey and Van der Loos 1970). Although differing from orientation minicolumns in this and other respects, the degree to which barrels interact with each other remains similarly controversial. Some investigators have suggested a prominent role for horizontal connections in creating receptive

The costs of publication of this article were defrayed in part by the payment of page charges. The article must therefore be hereby marked "advertisement" in accordance with 18 U.S.C. Section 1734 solely to indicate this fact. fields encompassing multiple neighboring vibrissae (Armstrong-James et al. 1991; Fox 1994), whereas others have proposed that interactions among neighboring whiskers reflect local, intrabarrel processing of multiwhisker thalamic inputs (Simons and Carvell 1989). In both visual and somatosensory cortices, horizontal connections are thought to contribute substantially to receptive field properties in nongranular layers.

To what extent do neighboring local circuits function independently of one another? Because of its anatomic organization, the somatosensory cortex of rodents is well suited for addressing this issue. A barrel consists of several thousand synaptically interconnected neurons, each of which receives the bulk of its afferent input from neurons in an homologous "barreloid" within the ventral posteromedial (VPM) thalamic nucleus (Land and Simons 1985). Neurons within the barrel and throughout its associated column are maximally excited by a principal whisker (PW) but, depending on laminar location, they respond also to neighboring whiskers to varying degrees (Armstrong-James and Fox 1987; Simons 1978). Deflection of two or more whiskers in rapid sequence reveals the presence of surround inhibitory effects that are considerably stronger in cortical than thalamic neurons (Brumberg et al. 1996; Simons and Carvell 1989).

Previously, we proposed that inhibitory interactions among neighboring whiskers in the layer IV barrel reflect direct engagement of local circuitry by thalamic inputs (Simons and Carvell 1989). We hypothesized that inputs to a barrel from nonprincipal whiskers arise directly from thalamic afferents, because neurons within thalamic barreloids, although driven most strongly by the PW, also respond robustly to neighboring whiskers (Nicolelis et al. 1993; Simons and Carvell 1989). The absence of a direct barrel-to-barrel pathway (Akhtar and Land 1989; Bernardo et al. 1990b; Hoeflinger et al. 1995) further supports the idea that barrels function independently of each other. Accordingly, destruction of a cortical barrel should have little, if any, effect on the influence of its corresponding whisker in neighboring barrels (see Fig. 1). Here we demonstrate that adjacent whisker-evoked excitation and inhibition within a barrel are virtually unaffected by ablation of the adjacent barrel.

\section{METHODS}

This study was conducted using adult female Sprague-Dawley rats (202-315 g; Hilltop). Surgery and anesthetic procedures were similar to those previously described (Brumberg et al. 1996). Briefly, animals were anesthetized with halothane $\left(\sim 1.5 \%\right.$ in a $50-50$ mixture of $\mathrm{N}_{2}$ and $\mathrm{O}_{2}$ ) and tracheotomized. Venous and arterial catheters were inserted for later drug delivery and blood pressure monitoring. The 
A

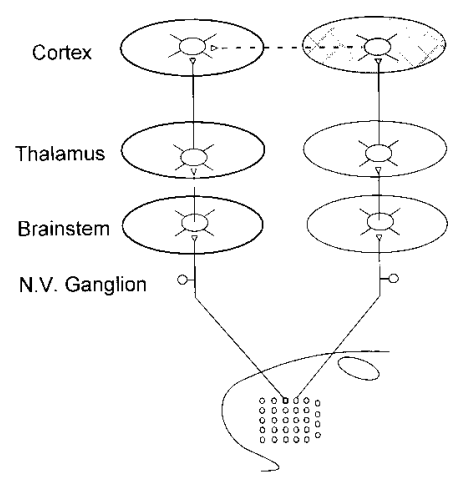

$\mathrm{B}$

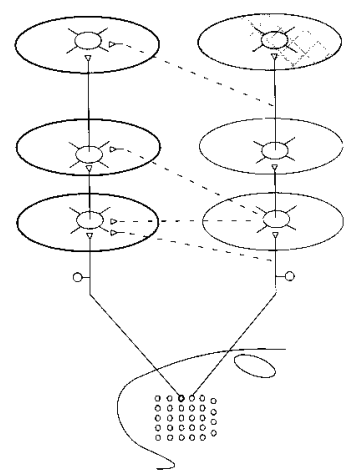

FIG. 1. Ablation of a cortical barrel can distinguish between 2 different circuits proposed to underlie adjacent whisker effects in barrel cortex. In $A$, adjacent whisker (AW) inputs come directly or indirectly from the adjacent cortical barrel, whereas in $B$ they originate from a number of possible, divergent subcortical projections (-- ). Ablation of an adjacent barrel (圖) should eliminate AW effects if circuit $A$ is correct, but should have no effect if $B$ is correct.

animal was placed in a stereotaxic frame, and a craniectomy was made in the skull overlying part of the whisker representation area of the right primary somatosensory cortex. A small steel post was attached to the skull with dental acrylic to hold the animal's head during the experiment. An acrylic dam was placed around the craniectomy and was kept filled with saline.

The underlying cortex was roughly mapped by multiunit recordings made through the dura using tungsten microelectrodes (Frederick Haer, Brunswick, ME; medium point, 3-5 M $\Omega$ at $1 \mathrm{kHz}$ ), combined with manual stimulation of the whiskers on the contralateral face. The dura was then removed over the cortical region of interest $(\sim 0.5 \times$ $1.0 \mathrm{~mm}$ ). The animal was taken off halothane, sedated with fentanyl (Sublimaze, Jannsen Pharmaceuticals; 5-10 $\mu \mathrm{g} \cdot \mathrm{kg}^{-1} \cdot \mathrm{h}^{-1}$ ), immobilized by pancuronium bromide $\left(\sim 1.6 \mathrm{mg} \cdot \mathrm{kg}^{-1} \cdot \mathrm{h}^{-1}\right)$, and artificially respired with a humidified 50-50 mixture of $\mathrm{N}_{2}$ and $\mathrm{O}_{2}$. Arterial blood pressure, heart rate, and tracheal airway pressure were monitored by a program written in LabVIEW 4.0 (National Instruments) running on a Power Macintosh 7100/66. Pupillary reflexes and electroencephalogram also were monitored. Ophthalmic ointment was placed over the eyes to prevent corneal drying.
A video camera attached via a beam-splitter to a surgical microscope was used to photograph the brain surface, using green light illumination to enhance blood vessel contrast. A detailed map of the targeted region of the barrelfield was then made using fine-tipped, glass/carbon fiber microelectrodes (see Kyriazi et al. 1996), with special attention being paid to the barrel chosen for ablation. To ablate a single barrel, an unused, high-impedance tungsten microelectrode (Frederick Haer: medium tip, 0.010-in. shank diameter, 10-12 M $\Omega$ at $1 \mathrm{kHz}$ ) was inserted normal to the pial surface overlying the estimated barrel center. To minimize dimpling of the brain surface and to achieve reproducible penetration depths, the electrode was advanced initially to a depth of $1,500 \mu \mathrm{m}$ and then withdrawn to $1,050 \mu \mathrm{m}$. Because preliminary experiments indicated that electrolytic lesions made with these electrodes produced a conical abscess that spread superficially, DC (30 $\mu \mathrm{A}$ for $30 \mathrm{~s}$, electrode negative) was passed initially at a depth of $1,050 \mu \mathrm{m}$ followed by a second application at $700 \mu \mathrm{m}$, which we routinely find to correspond to the layer III/IV boundary. Immediately thereafter spontaneous unit activity could be recorded deep to the lesion but not at middle or superficial cortical depths.

Subsequently, we examined the receptive field properties of units in a barrel/column (test barrel) immediately adjacent to the ablated barrel (see Fig. 1). We intentionally selected units that gave vigorous excitatory responses to the PW, because we assumed at the outset that such units were unlikely to be in close proximity to damaged tissue (but see RESULTS). Also, we assumed that suppression of such responses by adjacent whisker (AW) stimulation would be a robust indicator of intact inhibitory mechanisms within the test barrel. Unit recordings were obtained using double-barreled glass micropipettes, one barrel of which contained $3 \mathrm{M} \mathrm{NaCl}$ and the other $10 \% \mathrm{wt} / \mathrm{vol}$ horseradish peroxidase (HRP) for marking selected recording sites (Simons and Land 1987).

Electromechanical stimulators were used to deflect the test barrel's PW and two AWs (see Simons and Carvell 1989), one corresponding to the lesion-ablated barrel $\left(\mathrm{AW}_{\mathrm{L}}\right)$ and the other to an intact (normal) barrel $\left(\mathrm{AW}_{\mathrm{N}}\right)$ on another side of the test barrel (see Figs. 2 and 4$)$. The excitatory influence of each AW was quantified as the average number of spikes/stimulus taken over eight angles of deflection. Each deflection angle was repeated 10-20 times. Spike counts were measured during the 5-25 ms following stimulus onset. To quantify inhibitory AW effects, the AW was deflected in each of eight directions followed $20 \mathrm{~ms}$ later by PW deflection at its maximally effective angle. A
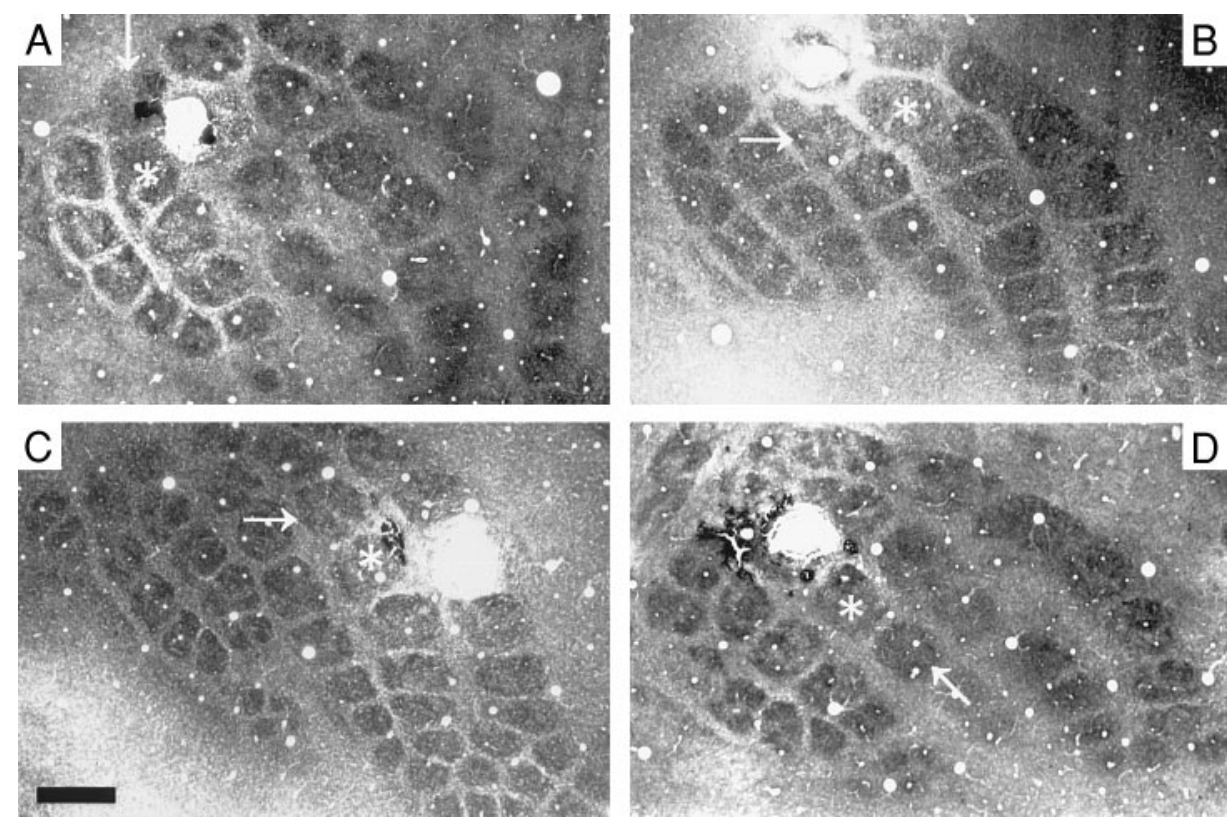

FIG. 2. Photomicrographs of barrel lesions from cytochrome oxidase-stained specimens. Electrolytic lesions (large, white areas) were made as described in METHODS. Test barrels are indicated by asterisks. Barrels whose corresponding whiskers were used as normal controls $\left(\mathrm{AW}_{\mathrm{N}}\right)$ are indicated by arrows. Scale bar is 500 $\mu \mathrm{m}$. Percentages of barrel destruction were estimated to be as follows: $A, 75 \%$ loss of barrel $\mathrm{C} 1$; $B, 100 \%$ loss of $\gamma ; C, 100 \%$ loss of $\mathrm{E} 3 ; D, 70 \%$ loss of $\mathrm{C} 1$. 
condition-test ratio (CTR) was calculated as the ratio of the average response to the $\mathrm{PW}$ when deflected after the AW to the response to PW deflection alone. Data from the responses evoked by the two AWs were compared using two-tailed paired-sample $t$-tests. For all trials in which at least one spike occurred during the stimulus onset window, the time of the first spike was measured at $0.1-\mathrm{ms}$ resolution, and the mean and modal latencies across all trials and deflection angles were determined. For modal latencies, spikes were placed in $0.5 \mathrm{~ms}$ bins, and the bin with the greatest number of spikes was taken as the mode. No modal latencies were returned for units in which no bin contained more than one spike. All data are expressed as means \pm SD unless indicated otherwise.

In two control experiments, the nerves innervating a whisker follicle were reversibly inactivated by infusion of $5 \mu \mathrm{l}$ of $4 \%$ lidocaine (Xylocaine, Astra USA). Under halothane anesthesia, a 30-gauge needle was inserted 2-3 mm into the hair follicle on the caudal side of the whisker (where the afferent fibers enter the capsule). PE-10 tubing connected the needle to a Hamilton syringe, and the entire assembly was positioned such that the needle was suspended in the approximate plane of the whisker. This minimized mechanical effects of the needle's presence on the mystacial pad and permitted attachment of a stimulator to the whisker.

At the conclusion of each experiment, animals were administered a lethal dose of pentobarbital sodium (Nembutal, Abbott Laboratories) and perfused transcardially with phosphate-buffered saline followed by a solution of $2 \%$ paraformaldehyde and $1.5 \%$ glutaraldehyde. Brains were sectioned on a freezing microtome in the tangential plane, and alternate sections were stained for HRP or cytochrome oxidase and counterstained with thionin. Lesions consisted of a large abscess fringed by a region of cellular disruption in which Nissl-stained neuronal cell bodies were clearly absent. We used the latter as a conservative estimate of the extent of direct physical damage.

\section{RES U L TS}

Data are reported from 12 experiments in which we estimate from serial tangential sections that, on average, $90 \%$ of a barrel was destroyed. Figure 2 shows photomicrographs of barrel fields from four experiments that illustrate the range of destruction as well as the locations of the test barrels. The distribution of lesion sizes, which ranged from $70-100 \%$ destruction, for all experiments is plotted in Fig. 3. In the vertical dimension, damage extended downward, having a blunt conical shape

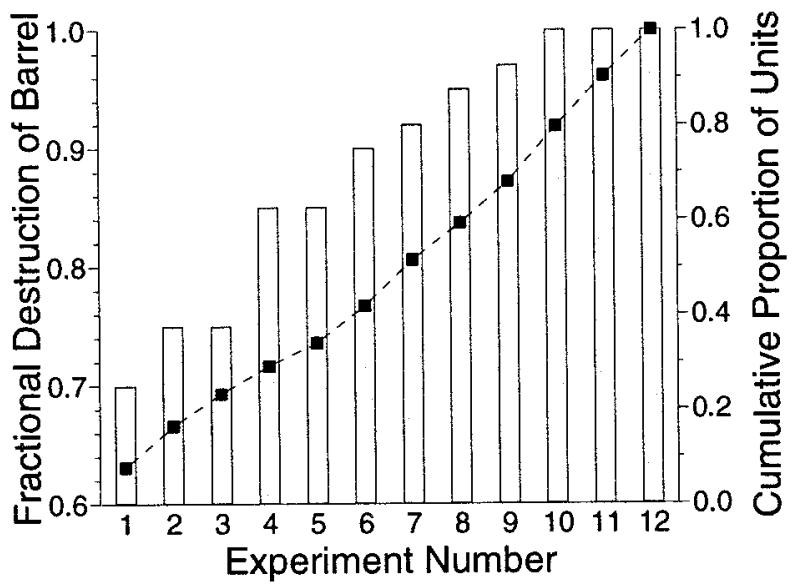

FIG. 3. Lesion sizes and corresponding distribution of recorded units. Bars

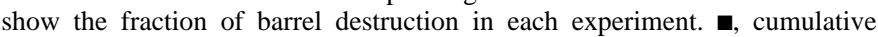
proportion of the 103 recorded units. Note that units are distributed roughly equally among the experiments; unit sampling was unbiased with respect to lesion size. whose apex extended well into layer V. From upper layer V through layers IV and lower layer III, the lesion was shaped cylindrically. More superficially, the lesion also tapered conically; the largest lesions extended almost to the pial surface. Lesions rarely extended into neighboring barrels but typically involved the septum between the lesion and the test barrel.

Dendrites of barrel neurons in rats have an average radius of $100 \mu \mathrm{m}$, and neurons near the barrel side can have dendrites that extend into the septum and even into the neighboring barrel (Simons and Woolsey 1984). We therefore classified the recorded units into two groups: those in the cytochrome oxidase-rich barrel center at least $100 \mu \mathrm{m}$ distant from the side of the barrel nearest the lesion (hereafter denoted as "Barrel") and those within this $100 \mu \mathrm{m}$ zone ("Near-lesion"). The latter included some cells located in the barrel side and possibly in the immediately adjacent septum. The relative proportions of units studied in experiments involving different lesion sizes were approximately equal (see Fig. 3). Because all lesions were extensive and because the number of units studied in each experiment was relatively small, we pooled data across experiments. All but 4 of 30 supragranular units were located above the barrel center; those 4 Near-lesion units were not included in the analyses.

Peristimulus-time histograms of recordings taken from the E2 barrel of an E1 barrel-ablated animal are shown in Fig. 4. The onset and offset of PW (E2) deflection elicit prominent excitatory responses. $\mathrm{AW}_{\mathrm{N}}(\mathrm{E} 3)$ evokes a clear, but weaker, excitatory response and a pronounced suppression of the response evoked by subsequent PW deflection. Most notably, the $\mathrm{AW}_{\mathrm{L}}$ (E1) also evokes virtually identical excitatory and inhibitory effects, despite the near-total ablation of the E1 barrel. On average, a Barrel unit's AW-evoked excitatory response was $\sim 20 \%$ that of its PW. Pooled Barrel results demonstrate that neither $\mathrm{AW}_{\mathrm{L}}$-evoked excitation nor $\mathrm{AW}_{\mathrm{L}}$-evoked inhibition were diminished by destruction of the AW's associated barrel (Fig. 5). Furthermore, there were no significant differences between the $\mathrm{AW}_{\mathrm{L}}$ and $\mathrm{AW}_{\mathrm{N}}$ latencies, either mean $(15.4 \pm 1.9$ $\mathrm{ms}, 15.9 \pm 1.4 \mathrm{~ms}$, mean $\pm \mathrm{SD}, n=27)$, or modal $(14.2 \pm 3.6$ $\mathrm{ms}, 15.4 \pm 3.3 \mathrm{~ms}, n=21$ ). The PW latencies (mean:12.9 \pm $1.7 \mathrm{~ms}, n=43$, modal: $11.6 \pm 2.2 \mathrm{~ms}, n=35$ ) were significantly shorter than those of either AW (all $P$ values $<0.001)$.

Near-lesion units displayed statistically significantly less $\mathrm{AW}_{\mathrm{L}}$-evoked excitation and inhibition compared with those evoked by $\mathrm{AW}_{\mathrm{N}}$. In addition, excitatory $\mathrm{AW}_{\mathrm{L}}$ responses were $42 \%$ smaller than those at locations more distant from the lesion, and these effects were greater with larger lesions $\left(R^{2}=\right.$ $0.47, P<0.001)$. PW-evoked excitatory responses in Nearlesion units also were slightly $(\sim 17 \%)$ but not significantly smaller than those of Barrel units. Interestingly, $\mathrm{AW}_{\mathrm{N}}$-evoked inhibition was stronger in Near-lesion than in Barrel units, and this, too, was correlated with lesion size $\left(R^{2}=47, P=0.007\right)$.

We also recorded from neurons in layers II/III superficial to the center of the test barrel (Fig. 5). Condition-test ratios evoked by $\mathrm{AW}_{\mathrm{L}}$ and $\mathrm{AW}_{\mathrm{N}}$ were not significantly different from each other. There was, however, a $54 \%$ reduction in the size of the $\mathrm{AW}_{\mathrm{L}}$-evoked excitatory response $(P=0.03$, paired $t$-test $)$; no correlation with lesion size was observed.

One possible explanation for the normal levels of $\mathrm{AW}_{\mathrm{L}^{-}}$ evoked excitation and inhibition observed in the Barrel recordings is that $\mathrm{AW}_{\mathrm{L}}$ effects were mediated by adjacent barrel 

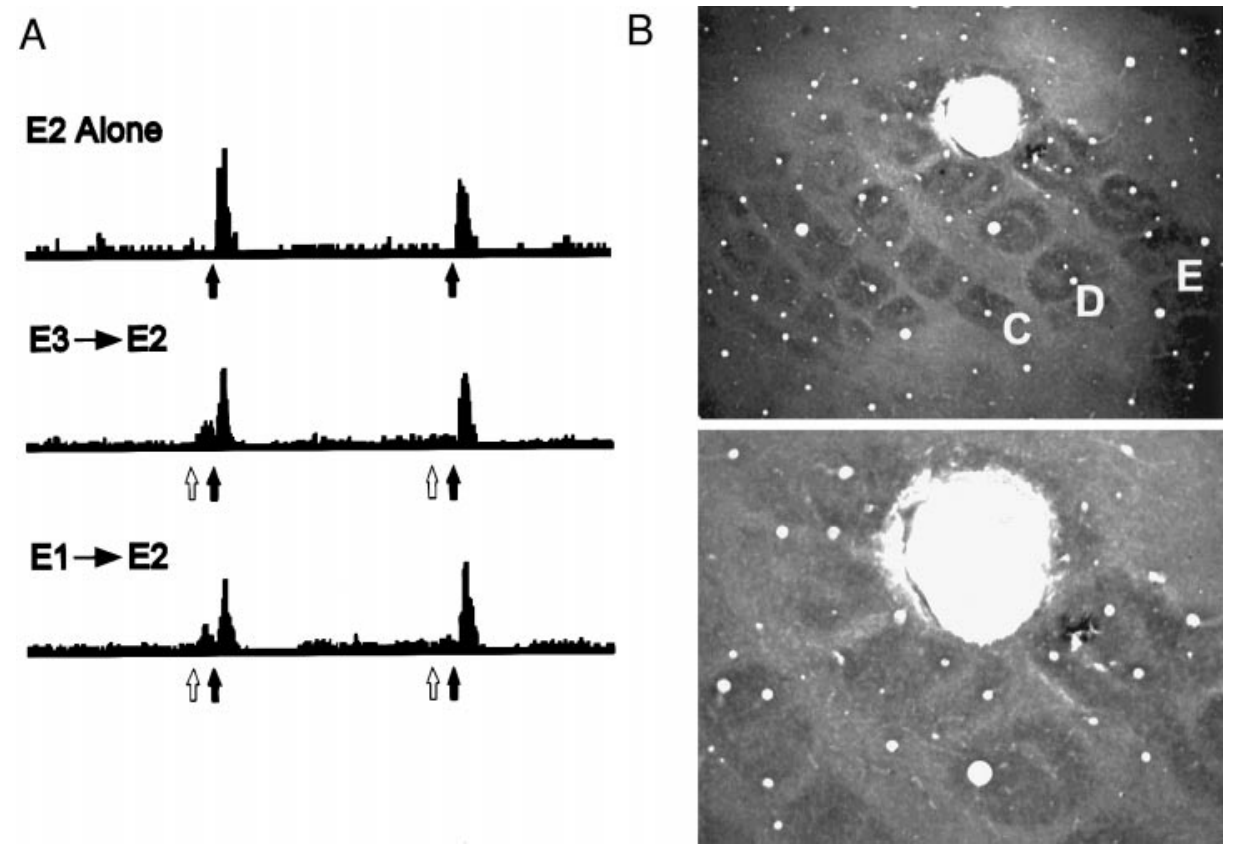

FIG. 4. Preservation of $\mathrm{AW}_{\mathrm{L}}$ excitatory and inhibitory effects following near-total destruction of its corresponding barrel. A: peristimulustime histograms of activity recorded within the E2 barrel, $>100 \mu \mathrm{m}$ from the barrel edge by the lesion, in response to deflection of the principal whisker (PW) alone (top), or after deflection of adjacent whisker E3 (middle) or E1 (bottom). Filled arrows, times of onset and offset of PW deflection; open arrows, onset and offset of AW deflection. $B$ : micrographs of a $60-\mu \mathrm{m}$ section taken through layer IV of the barrelfield, shown at different magnifications. Note that despite the near-total (estimated to be $97 \%$ ) destruction of the E1 barrel in this animal, whisker E1 elicits excitatory and inhibitory effects within the E2 barrel ( $A$, bottom trace) that are indistinguishable from the effects elicited by whisker E3, whose barrel is intact ( $A$, middle trace).

remnants that may have survived the lesion and continued to communicate with the test barrel by means of direct, straightline connections across the interbarrel septum (see Fox 1994). We therefore performed one experiment in which 14 additional, smaller lesions $(10 \mu \mathrm{a}, 10 \mathrm{~s})$ were made in 7 penetrations, at 1,050 and $700 \mu \mathrm{m}$ depths, in a line along the septal region between the ablated adjacent barrel and the test barrel. This procedure resulted in extensive damage to both the ablated barrel and the intervening septum and eliminated any possibility of direct, straight-line barrel-to-barrel communication. Nevertheless, $\mathrm{AW}_{\mathrm{L}}$-evoked excitation and inhibition remained at normal levels (Barrel, spikes/stimulus: $\mathrm{AW}_{\mathrm{L}}=$ $0.65 \pm 0.28, \mathrm{AW}_{\mathrm{N}}=0.69 \pm 0.30 ;$ condition-test ratio: $\left.\mathrm{AW}_{\mathrm{L}}=0.50 \pm 0.15, \mathrm{AW}_{\mathrm{N}}=0.56 \pm 0.15 ; n=5\right)$.

Another possible explanation for the ineffectiveness of the lesion is that slight, unintended movements of the test barrel's PW that occur on AW deflection directly activate the test barrel. This may be of particular concern when the PW remains held by a stationary stimulator during AW deflection (Simons 1985). To address this issue, we performed two experiments in

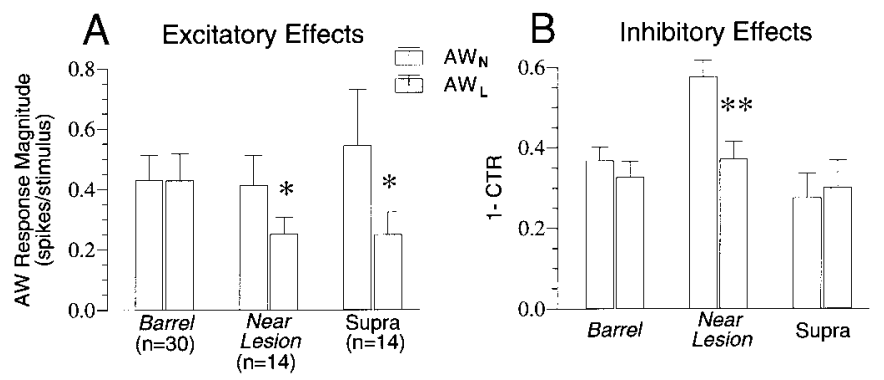

FIG. 5. Magnitude of excitatory $(A)$ and inhibitory $(B)$ effects of adjacent whisker deflection in Barrel, Near Lesion, and supragranular units. $\mathrm{AW}_{\mathrm{N}}$ and $\mathrm{AW}_{\mathrm{L}}$ designate responses to deflection of the normal and lesion-ablated barrel's adjacent whiskers, respectively. The degree of inhibition evoked by the 2 whiskers is expressed as 1 - CTR (Condition Test Ratio), such that a greater value indicates greater surround inhibition. Error bars indicate mean \pm $\mathrm{SE}$; $* P<0.05$; $* * P<0.001$, in paired $t$-test. Note that within the center of the test barrel, the $\mathrm{AW}_{\mathrm{N}}$ and $\mathrm{AW}_{\mathrm{L}}$ evoke statistically indistinguishable levels of excitation and inhibition. which the peripheral nerves innervating the PW were reversibly inactivated by injection of lidocaine into the follicle. Immediately after injection, units in the test barrel were completely unresponsive to the PW and partially responsive to the AW. Within 45 min after injection, AW-evoked excitation had recovered to near-normal levels, whereas responses to the (anesthetized) PW were absent entirely or reduced to below AW levels for an additional 15-60 min. We therefore consider it unlikely that mechanical transmission across the mystacial pad accounts for the bulk of the $\mathrm{AW}_{\mathrm{L}}$, or $\mathrm{AW}_{\mathrm{N}}$, response in the test barrel.

\section{I S C U S S I O N}

The major finding of this study is the remarkable preservation in the center of the test barrel of AW-evoked excitatory and inhibitory effects despite near-total ablation of the AW's barrel. We consider layer VI neurons deep to the lesion an unlikely source of the normal levels of $\mathrm{AW}_{\mathrm{L}}$-evoked effects, because at the minimum their apical dendrites were severely damaged by the lesion, which extended well into layer $\mathrm{V}$. Results support our hypothesis that thalamic afferents normally provide direct excitatory AW input to a barrel (Fig. $1 B$ ). These thalamic inputs may originate from multiwhisker neurons in the homologous thalamic barreloid (Brumberg et al. 1996; Simons and Carvell 1989) and/or from neurons in adjacent, nonhomologous barreloids (Land et al. 1995; Land and Simons 1985). Further, AW-evoked inhibition is, on average, weaker in barreloid than barrel neurons. The observation of normal levels of $\mathrm{AW}_{\mathrm{L}}$-evoked inhibition in the test barrel is consistent with the idea that thalamic activation of barrel circuitry on AW stimulation evokes surround inhibition by a feed-forward, intrabarrel mechanism, enhancing the response tuning of barrel neurons (Brumberg et al. 1996; Kyriazi and Simons 1993; Simons and Carvell 1989).

We attribute the abnormalities observed in Near-lesion cells to altered synaptic circuitry resulting from direct damage to thalamic afferents and/or dendritic processes of test barrel 
neurons. Lesion by-products, e.g., elevated levels of extracellular potassium or glutamate, may also have contributed to Near-lesion abnormalities. If excitatory by-products disproportionately affect inhibitory barrel neurons, which are normally highly excitable, this could account for the somewhat paradoxical finding that $\mathrm{AW}_{\mathrm{N}}$-evoked inhibition was greater in Nearlesion than in Barrel units. In either case, the fact that receptive field abnormalities are observed in some neurons (Near-lesion) but not in other, more distant ones (Barrel) residing in the same barrel suggests that a barrel may contain several relatively independent subnetworks (see Chmielowska et al. 1989; McCasland et al. 1992). The nature and sizes of such possible circuits, and the degree to which they may or may not interact, remain to be determined.

In contrast to results in layer IV, adjacent barrel lesion led to a clear reduction in $\mathrm{AW}_{\mathrm{L}}$ responses recorded in layers superficial to the test barrel. We suggest that AW input normally reaches supragranular layers via several pathways (see Bernardo et al. 1990a,b; Gottlieb and Keller 1997): 1) an intracolumnar, vertical pathway originating within the test barrel itself, 2) a pathway originating in the adjacent barrel, which includes an additional horizontal, intercolumnar component within the supragranular layers, and 3) recurrent collaterals from infragranular neurons deep to the adjacent barrel. The lesions eliminated the second and possibly the third of these routes.

The present findings in layer IV differ markedly from those of two previous studies, which used a similar experimental paradigm but in urethan-anesthetized animals (ArmstrongJames et al. 1991; Fox 1994). In those studies, barrel lesion reduced excitatory $\mathrm{AW}_{\mathrm{L}}$ responses in proportion to the extent of the lesion, and modal latencies increased from 15.2 to 24.3 ms. Inhibitory interactions were not assessed. The authors concluded that direct barrel-to-barrel connections normally mediate AW responses (see Fig. 1A). In the study of Armstrong-James et al., the mean barrel destruction was 58\% compared with $90 \%$ in the present study. Moreover, it appears that the present lesions extended deeper and more superficially (judging from Fig. 4 in Armstrong-James et al. 1991). Although Armstrong-James and colleagues did not categorize the barrel units with respect to their proximity to the lesion, as done here, it is clear from their METHODS section that most of their data were obtained $>100 \mu \mathrm{m}$ from the side of the barrel closest to the lesion. Thus differences in results cannot be explained by differences in the location of the recorded units or by differences in lesion size.

The most likely explanation for the discrepant findings is that AW-evoked excitatory responses are qualitatively different in the two experimental preparations. In terms of AW response latency and magnitude, relative to PW responses, the present data are comparable to values obtained previously in awake, undrugged rats (Simons et al. 1992). As discussed in that study, urethan anesthesia increases the magnitude and duration of AW-evoked responses, possibly through involvement of $N$-methyl-D-aspartate (NMDA) receptors (see Armstrong-James et al. 1993). After exposure of tangential barrel field slices to bicuculline methiodide, NMDA-dependent paroxysmal discharges can propagate across the barrel field (Fleidervish et al. 1998). Thus it appears that long latency, longduration, barrel-dependent AW responses are expressed under conditions where NMDA-dependent synaptic transmission may be more prominent.

Taken together with results of previous modeling studies (Kyriazi and Simons 1993; Pinto et al. 1996), the present findings demonstrate that local, intrabarrel circuitry is sufficient to account for the integration, both excitatory and inhibitory, of multiwhisker information within individual layer IV barrels. Although there are almost certainly some means for barrels to influence each other, directly or indirectly, interactions are likely to be modulatory, perhaps contributing to the overall excitability of the barrel field during different behavioral states (see McCasland et al. 1997 for a discussion). Whatever role such interactions might play, available anatomic and physiological evidence indicates that barrels function as an array of independent, parallel processors of afferent information. Accordingly, barrel circuitry transforms multiple-whisker inputs into predominantly single-whisker outputs, which are then distributed to other layers of the cortical column, where larger and more complexly organized receptive fields are synthesized via intercolumnar connections.

We are especially grateful to R. Bruno for extensive participation in preliminary studies and to J. Brumberg for help with some of the experiments.

This work was supported by National Institute of Neurological Disorders and Stroke Grant NS-19950.

Present address of D. Goldreich: Dept. of Occupational Therapy, Duquesne University, Pittsburgh, PA 15282.

Address reprint requests to D. J. Simons.

Received 2 February 1999; accepted in final form 13 May 1999.

\section{REFERENCES}

AKHTAR, N. D. AND LAND, P. W. Intrinsic connections of rat SmI barrel cortex. Soc. Neurosci. Abstr. 15: 312, 1989.

Armstrong-James, M., Callahan, C. A., and Friedman, M. A. Thalamocortical processing of vibrissal information in the rat. I. Intracortical origins of surround but not centre-receptive fields of layer IV neurones in the rat S1 barrel field cortex. J. Comp. Neurol. 303: 193-210, 1991.

ARMSTRONG-James, M. AND Fox, K. Spatiotemporal convergence and divergence in the rat SI "barrel" cortex. J. Comp. Neurol. 263: 265-281, 1987. Armstrong-James, M., Welker, E., and Callahan, C. A. The contribution of NMDA and non-NMDA receptors to fast and slow transmission of sensory information in the rat SI barrel cortex. J. Neurosci. 13: 2149-2160, 1993.

Bernardo, K. L., McCasland, J. S., and Woolsey, T. A. Local axonal trajectories in mouse barrel cortex. Exp. Brain Res. 82: 247-253, 1990a.

Bernardo, K. L., McCasland, J. S., Woolsey, T. A., and Strominger, R. N. Local intra- and interlaminar connections in mouse barrel cortex. J. Comp. Neurol. 291: 231-255, 1990b.

Brumberg, J. C., Pinto, D., And Simons, D. J. Spatial gradients and inhibitory summation in the rat whisker barrel system. J. Neurophysiol. 76: 130-140, 1996.

Chmielowska, J., Carvell, G. E., And Simons, D. J. Spatial organization of thalamocortical and corticothalamic projection systems in the rat SmI barrel cortex. J. Comp. Neurol. 285: 325-338, 1989.

Crook, J. M., Kisvardy, Z. F., AND Eysel, U. T. GABA-induced inactivation of functionally characterized sites in cat striate cortex: Effects on orientation tuning and direction selectivity. Vis. Neurosci. 14: 141-158, 1997.

FERSTER, D. Origin of orientation-selective EPSPs in simple cells of cat visual cortex. J. Neurosci. 7: 1780-1791, 1987.

FERSTER, D. Spatially opponent excitation and inhibition in simple cells of the cat visual cortex. J. Neurosci. 8: 1172-1180, 1988.

Fleidervish, I. A., BinshtoK, A. M., AND GutNick, M. J. Functionally distinct NMDA receptors mediate horizontal connectivity within layer 4 of mouse barrel cortex. Neuron 21: 1055-1065, 1998.

Fox, K. The cortical component of experience-dependent synaptic plasticity in the rat barrel cortex. J. Neurosci. 14: 7665-7679, 1994.

GotTlieb, J. P. AND KelLeR, A. Intrinsic circuitry and physiological properties of pyramidal neurons in rat barrel cortex. Exp. Brain Res. 115: 47-60, 1997. 
Hoeflinger, B. F., Bennett-Clarke, C. A., Chiaia, N. L., Killackey, H. P., AND RHOADES, R. W. Patterning of local intracortical projections within the vibrissae representation of rat primary somatosensory cortex. J. Comp. Neurol. 354: 551-563, 1995.

Hubel, D. H. AND Wiesel, T. N. Receptive fields, binocular interaction and functional architecture in the cat's visual cortex. J. Physiol. (Lond.) 160: 106-154, 1962.

Kyriazi, H. T., Carvell, G. E., Brumberg, J. C., and Simons, D. J. Quantitative effects of GABA and bicuculline methiodide on receptive field properties of neurons in real and simulated whisker barrels. J. Neurophysiol. 75: 547-560, 1996.

KyRIAZI, H. T. AND Simons, D. J. Thalamocortical response transformations in simulated whisker barrels. J. Neurosci. 13: 1601-1615, 1993.

LAND, P. W., Buffer, S. A., JR., AND YAskosky, J. D. Barreloids in adult rat thalamus: three dimensional architecture and relationship to somatosensory cortical barrels. J. Comp. Neurol. 355: 573-588, 1995.

LAND, P. W. AND Simons, D. J. Metabolic and structural correlates of the vibrissae representation in the thalamus of the adult rat. Neurosci. Lett. 60: 319-324, 1985.

McCasland, J. S., Hibbard, L. S., Kalmbach, S., and Woolsey, T. A. Cellular maps of metabolic activity in antigenically identified neurons: a 2-deoxyglucose/immunostaining approach to barrel field circuitry. Soc. Neurosci. Abstr. 18: 1546, 1992.

McCasland, J. S., Hibbard, L. S., Rhoades, R. W., and Woolsey, T. A. Activation of a wide-spread network of inhibitory neurons in barrel cortex. Somatosens. Mot. Res. 14: 138-147, 1997.

Nicolelis, M. A., Lin, R.C.S., Woodward, D. J., And Chapin, J. K. Dynamic and distributed properties of many-neuron ensembles in the ventral posterior medial thalamus of awake rats. Proc. Natl. Acad. Sci. USA 90: 2212-2216, 1993
Pinto, D. J., Brumberg, J. C., Simons, D. J., And Ermentrout, G. B. A quantitative population model of whisker barrels: Re-examining the WilsonCowan equations. J. Comput. Neurosci. 3: 247-264, 1996.

ReID, C. R. AND Alonso, J.-M. Specificity of monosynaptic connections from thalamus to visual cortex. Nature 378: 281-284, 1995.

Sillito, A. M., Kemp, J. A., Milson, J. A., And Beradi, N. A re-evaluation of the mechanisms underlying simple cell orientation selectivity. Brain Res. 194: 517-520, 1980 .

SimONS, D. J. Response properties of vibrissa units in the rat SI somatosensory neocortex. J. Neurophysiol. 41: 798-820, 1978.

Simons, D. J. Temporal and spatial integration in the rat SI vibrissa cortex. J. Neurophysiol. 54: 615-635, 1985.

Simons, D. J. AND CARvell, G. E. Thalamocortical response transformation in the rat vibrissa/barrel system. J. Neurophysiol. 61: 311-330, 1989.

Simons, D. J., Carvell, G. E., Hershey, A. E., and Bryant, D. P. Responses of barrel cortex neurons in awake rats and effects of urethane anesthesia. Exp. Brain Res. 91: 259-272, 1992.

SimONS, D. J. AND LAND, P. W. A reliable technique for marking the location of extracellular recording sites using glass micropipettes. Neurosci. Lett. 81: 100-104, 1987

Simons, D. J. And Woolsey, T. A. Morphology of Golgi-Cox-impregnated barrel neurons in rat SmI cortex. J. Comp. Neurol. 230: 119-132, 1984.

Troyer, T. W., Krukowski, A. A., Priebe, N. J., And Miller, K. D. Contrastinvariant orientation tuning in cat visual cortex: thalamocortical input tuning and correlation-based intracortical connectivity. J. Neurosci. 18: 59085927,1998

WOOLSEY, T. A. AND VAN DER LOOS, H. The structural organization of layer IV in the somatosensory region (SI) of mouse cerebral cortex. Brain Res. 17: 205-242, 1970 . 